\title{
BILANGAN KROMATIK LOKASI PADA GRAF PRISMA BEREKOR
}

\author{
EKA RAHAYU NENGSIH A, DES WELYYANTI, EFFENDI \\ Program Studi S1 Matematika, \\ Fakultas Matematika dan Ilmu Pengetahuan Alam, Universitas Andalas, \\ Kampus UNAND Limau Manis Padang, Indonesia. \\ email : ekarahayu826@gmail.com
}

Diterima 9 Maret 2019 Direvisi 7 April 2019 Dipublikasikan 7 Mei 2019

\begin{abstract}
Abstrak. Misalkan $G=(V, E)$ suatu graf terhubung dan c suatu k-pewarnaan dari $G$. Kelas warna pada $G$ adalah himpunan titik-titik yang berwarna $i$, dinotasikan dengan $S_{i}$ untuk $1 \leq i \leq k$. Misalkan $\Pi=\left\{S_{1}, S_{2}, \cdots, S_{k}\right\}$ adalah partisi terurut dari $V(G)$ berdasarkan pewarnaan titik. Kode warna $c_{\Pi}(v)$ dari suatu titik $v \in V(G)$ didefinisikan sebagai vektor- $k$ :

$$
c_{\Pi}(v)=\left(d\left(v, S_{1}\right), d\left(v, S_{2}\right), \cdots, d\left(v, S_{k}\right)\right)
$$

dimana $\left.d\left(v, S_{i}\right)=\min \left\{d(v, x) \mid x \in S_{i}\right)\right\}$, untuk $1 \leq i \leq k$. Jika setiap titik yang berbeda di $G$ memiliki kode warna yang berbeda untuk suatu $\Pi$, maka c disebut pewarnaan lokasi untuk $G$. Jumlah warna minimum yang digunakan pada pewarnaan lokasi dari graf $G$ disebut bilangan kromatik lokasi untuk $G$, dinotasikan dengan $\chi_{L}(G)$. Pada penelitian ini akan dibahas tentang penentuan bilangan kromatik lokasi pada graf prisma berekor.
\end{abstract}

Kata Kunci: Bilangan Kromatik Lokasi, Graf Prisma Berekor, Kode warna

\section{Pendahuluan}

Konsep bilangan kromatik lokasi merupakan kasus khusus dari dimensi partisi dan pewarnaan suatu graf. Konsep pewarnaan graf melahirkan konsep bilangan kromatik. Konsep bilangan kromatik sangat menarik untuk dikaji dan mempunyai penerapan yang menarik dalam berbagai masalah [3].

Penerapan bilangan kromatik untuk suatu graf sangat beragam. Diantaranya pengaturan jadwal, penempatan barang dari beberapa objek yang berbeda, penempatan bahan kimia, dan masalah pengaturan waktu pada lampu lalu lintas di suatu persimpangan jalan [1].

Graf prisma berekor $\left(X_{m, n}\right)$ adalah graf yang dibentuk dari $m C_{3}$ dengan cara sebagai berikut. Notasikan $C_{3}^{j}$ sebagai $C_{3}$ ke-j untuk $1 \leq j \leq m$, dengan $V\left(C_{3}^{j}\right)=\left\{v_{1_{j}}, v_{2_{j}}, v_{3_{j}}\right\}$. Graf prisma berekor kontruksi dengan cara menambahkan sisi $v_{i_{j}} v_{i_{j+1}}$ untuk $1 \leq i \leq 3$ dan $1 \leq j \leq m-1$ serta menambahkan daun sebanyak $n$ ke titik $v_{i}$, untuk $1 \leq i \leq 3$ dan $1 \leq j \leq m$ dinotasikan titik-titik pada daun sebagai $v_{i_{j, k}}$ untuk $1 \leq i \leq 3,1 \leq j \leq m$ dan $1 \leq k \leq n$. Pada tugas akhir ini akan dicari adalah bilangan kromatik lokasi pada graf prisma berekor. 
Bilangan kromatik (chromatic number) dari graf $G$ adalah bilangan asli terkecil $k$ sedemikian sehingga $G$ mempunyai suatu pewarnaan- $k$ titik sejati. Bilangan kromatik dari $G$ dinotasikan dengan $\chi(G)$. Misalkan $\chi(G)=k$, ini berarti titiktitik di $G$ paling kurang diwarnai dengan $k$ warna dan tidak dapat diwarnai dengan $k-1$ warna. Jika titik-titik di $G$ diwarnai dengan $k$ warna maka tidak ada titik yang bertetangga mempunyai warna yang sama.

Misalkan $S_{i}$ himpunan titik yang diberi warna $i$ dengan $1 \leq i \leq k$, disebut kelas warna, dimana $\Pi=\left\{S_{1}, S_{2}, \cdots, S_{k}\right\}$ adalah himpunan yang terdiri dari kelas-kelas warna dari $V(G)$. Titik $v \in C_{i}$ disebut titik dominan jika $d\left(v, S_{i}\right)=0$ dan $d\left(v, S_{j}\right)=1$ untuk $i \neq j$. Kode warna $c_{\Pi}(v)$ dari $v$ adalah $k$-pasang terurut

$$
\left(d\left(v, S_{1}\right), d\left(v, S_{2}\right), \cdots, d\left(v, S_{k}\right)\right)
$$

dimana $d\left(v, S_{i}\right)=\min \left\{d(v, x): x \in S_{i}\right\}$, untuk $1 \leq i \leq k$. Jika setiap titik di $G$ memiliki kode warna yang berbeda, maka $c$ disebut pewarnaan lokasi dari $G$. Banyaknya warna minimum yang digunakan sedemikian sehingga $G$ mempunyai pewarnaan lokasi disebut bilangan kromatik lokasi dari $G$ dan dinotasikan dengan $\chi_{L}(G)$.

Chartrand dkk.(2002) telah memberikan teorema dasar bilangan kromatik lokasi suatu graf. Teorema tersebut dijelaskan pada teorema-teorema di bawah ini. $N(v)$ sebagai himpunan yang berisi semua titik yang menjadi tetangga dari $v$.

Teorema 1.1. [2] Misal c adalah suatu pewarnaan lokasi pada graf terhubung $G$. Jika $u$ dan $v$ adalah dua titik pada graf $G$ sedemikian sehingga $d(u, w)=d(v, w)$ untuk setiap $w \in V(G) \backslash\{u, v\}$, maka $c(u) \neq c(v)$. Dalam hal khusus, jika $u$ dan $v$ adalah titik-titik yang tidak bertetangga di $G$ sedemikian sehingga $N(u)=N(v)$, $\operatorname{maka} c(u) \neq c(v)$.

Akibat 1.2. [2] Jika $G$ adalah suatu graf terhubung yang memuat suatu titik yang bertetangga dengan $k$ daun di $G$, maka $\chi_{L}(G) \geq k+1$.

\section{Bilangan Kromatik Lokasi pada Graf Prisma Berekor}

Pada bagian ini akan dibahas tentang bilangan kromatik lokasi dari graf prisma berekor, dinotasikan sebagai $X_{2, n}$ untuk $n \geq 1$.

Teorema 2.1. Jika $X_{m, n}$ adalah graf prisma berekor, maka:

$$
\chi_{L}\left(X_{2, n}\right)= \begin{cases}4 & \text { untuk } n=1,2,3, \\ n+1, & \text { untuk } n \geq 4 .\end{cases}
$$

Bukti. Misalkan terdapat graf prisma berekor $X_{2, n}$ dengan $n \geq 1$.

Kasus 1. Akan ditunjukkan bahwa $\chi_{L}\left(X_{2, n}\right)=4$, untuk $n=1,2,3$.

Karena $X_{2,1}$ dan $X_{2,2}$ adalah subgraf dari $X_{2,3}$, maka cukup dibuktikan bilangan kromatik lokasi pada $X_{2,3}$. Hal ini dapat dilihat pada Gambar 1.

Pertama akan ditunjukkan bahwa $\chi_{L}\left(X_{2,3}\right) \geq 4$. Perhatikan bahwa pada graf $X_{2,3}$ terdapat dua $C_{3}$ yaitu $C_{3}^{1}$ dan $C_{3}^{2}$. Pada $C_{3}^{1}$ tiap titik saling bertetangga sehingga dibutuhkan minimal tiga pewarnaan lokasi. Selanjutnya, untuk $C_{3}^{2}$ jika diberikan 
tiga pewarnaan lokasi seperti pada $C_{3}^{1}$ maka terdapat kode warna yang sama maka tidak cukup dengan tiga pewarnaan lokasi. Agar $X_{2,3}$ memiliki kode warna yang berbeda maka haruslah $\chi_{L}\left(X_{2,3}\right) \geq 4$.

Selanjutnya, akan ditunjukkan bahwa $\chi_{L}\left(X_{2,3}\right) \leq 4$. Definisikan $c: V\left(X_{2,3}\right) \rightarrow$ $\{1,2,3,4\}$ sebagai berikut:

$c\left(v_{1_{2}}\right)=c\left(v_{1_{1,1}}\right)=c\left(v_{2_{1,1}}\right)=c\left(v_{3_{1,1}}\right)=1$,

$c\left(v_{2_{2}}\right)=c\left(v_{3_{1}}\right)=c\left(v_{1_{1,2}}\right)=c\left(v_{2_{1,2}}\right)=2$,

$c\left(v_{2_{1}}\right)=c\left(v_{3_{2}}\right)=c\left(v_{1_{1,3}}\right)=c\left(v_{3_{1,2}}\right)=3$,

$c\left(v_{1_{1}}\right)=c\left(v_{2_{1,3}}\right)=c\left(v_{3_{1,3}}\right)=4$.

Berdasarkan konstruksi tersebut diperoleh kelas warna sebagai berikut:

$$
\begin{aligned}
& S_{1}=\left\{v_{1_{2}}, v_{1_{1,1}}, v_{2_{1,1}}, v_{3_{1,1}}\right\} \\
& S_{2}=\left\{v_{2_{2}}, v_{3_{1}}, v_{1_{1,2}}, v_{2_{1,2}}\right\} \\
& S_{3}=\left\{v_{2_{1}}, v_{3_{2}}, v_{1_{1,3}}, v_{3_{1,2}}\right\} \\
& S_{4}=\left\{v_{1_{1}}, v_{2_{1,3}}, v_{3_{1,3}}\right\} .
\end{aligned}
$$

Akibatnya, diperoleh kode warna setiap titik di $X_{2,3}$ terhadap $\Pi=\left\{S_{1}, S_{2}, S_{3}, S_{4}\right\}$

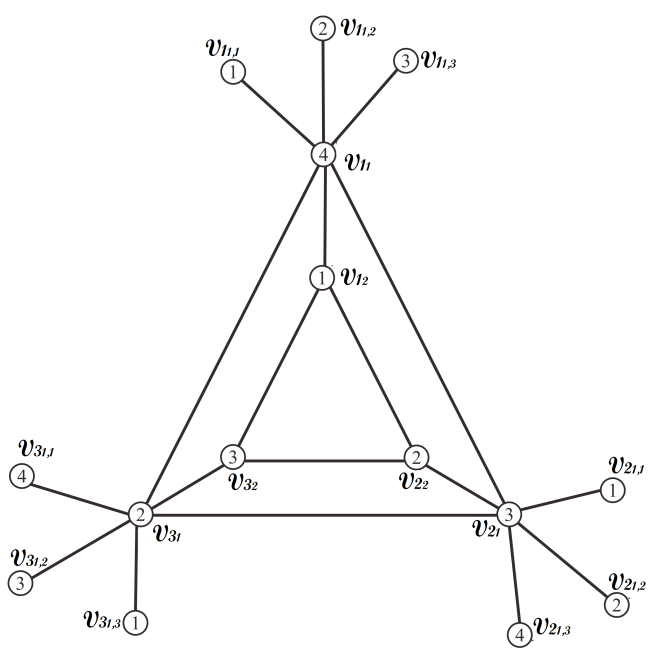

Gambar 1. Pewarnaan-4 lokasi untuk $X_{2,3}$

sebagai berikut:

$$
\begin{aligned}
& c_{\Pi}\left(v_{1_{1}}\right)=(1,1,1,0), \\
& c_{\Pi}\left(v_{2_{1}}\right)=(1,1,0,1), \\
& c_{\Pi}\left(v_{3_{1}}\right)=(1,0,1,1), \\
& c_{\Pi}\left(v_{1_{2}}\right)=(0,1,1,1) \text {, } \\
& c_{\Pi}\left(v_{2_{2}}\right)=(1,0,1,2) \text {, } \\
& c_{\Pi}\left(v_{1_{1,1}}\right)=(0,2,2,1) \text {, } \\
& c_{\Pi}\left(v_{1_{1,2}}\right)=(2,0,2,1) \text {, } \\
& c_{\Pi}\left(v_{3_{2}}\right)=(1,1,0,2), \\
& c_{\Pi}\left(v_{2_{1,1}}\right)=(0,2,1,2) \text {, } \\
& c_{\Pi}\left(v_{2_{1,2}}\right)=(2,0,1,2) \text {, } \\
& c_{\Pi}\left(v_{1_{1,3}}\right)=(2,2,0,1) \text {, } \\
& c_{\Pi}\left(v_{3_{1,1}}\right)=(0,1,2,2) \text {, } \\
& c_{\Pi}\left(v_{3_{1,2}}\right)=(2,1,0,2) \text {, } \\
& c_{\Pi}\left(v_{2_{1,3}}\right)=(2,2,1,0) \text {, } \\
& c_{\Pi}\left(v_{3_{1,3}}\right)=(2,1,2,0) \text {. }
\end{aligned}
$$


Karena setiap titik pada $X_{2,3}$ memiliki kode warna yang berbeda maka $c$ merupakan pewarnaan-4 lokasi pada $X_{2,3}$ sehingga, diperoleh bahwa $\chi_{L}\left(X_{2,3}\right) \leq 4$. Jadi, $\chi_{L}\left(X_{2,3}\right)=4$.

Kasus 2. Akan ditunjukkan bahwa $\chi_{L}\left(X_{2, n}\right)=n+1$, untuk $n \geq 4$.

Akan ditunjukkan bahwa $\chi_{L}\left(X_{2, n}\right) \geq n+1$. Dengan menggunakan Akibat 2.3.2, diperoleh $\chi_{L}\left(X_{2, n}\right) \geq n+1$. Selanjutnya, akan ditunjukkan bahwa $\chi_{L}\left(X_{2, n}\right) \leq$ $n+1$. Pada Gambar 2. diperlihatkan pewarnaan-4 lokasi untuk $X_{2, n}$. Didefinisikan $c: V\left(X_{2, n}\right) \rightarrow[1, n+1]$ dimana $[1, n+1]$ menyatakan bilangan bulat dari 1 sampai $n+1$ sebagai berikut:

$c\left(V_{1_{2}}\right)=c\left(V_{1_{1,1}}\right)=c\left(V_{2_{1,1}}\right)=c\left(V_{3_{1,1}}\right)=1$,

$c\left(V_{2_{2}}\right)=c\left(V_{3_{1}}\right)=c\left(V_{1_{1,2}}\right)=c\left(V_{2_{1,2}}\right)=2$,

$c\left(V_{2_{1}}\right)=c\left(V_{3_{2}}\right)=c\left(V_{1_{1,3}}\right)=c\left(V_{3_{1,2}}\right)=3$,

$c\left(V_{1_{1}}\right)=c\left(V_{2_{1,3}}\right)=c\left(V_{3_{1,3}}\right)=4$,

$c\left(v_{i_{1, k}}\right)=[1, n+1] \backslash c\left(v_{i_{1}}\right)$ untuk $1 \leq i \leq 3$ dan $1 \leq k \leq n$.

Berdasarkan konstruksi tersebut diperoleh kelas warna sebagai berikut:

$$
\begin{aligned}
S_{1} & =\left\{v_{1_{2}}, v_{1_{1,1}}, v_{2_{1,1}}, v_{3_{1,1}}\right\}, \\
S_{2} & =\left\{v_{2_{2}}, v_{3_{1}}, v_{1_{1,2}}, v_{2_{1,2}}\right\}, \\
S_{3} & =\left\{v_{2_{1}}, v_{3_{2}}, v_{1_{1,3}}, v_{3_{1,2}}\right\}, \\
S_{4} & =\left\{v_{1_{1}}, v_{2_{1,3}}, v_{3_{1,3}}\right\}, \\
S_{n+1} & =\left\{v_{1_{1, n}}, v_{2_{1, n}}, v_{3_{1, n}}\right\}
\end{aligned}
$$

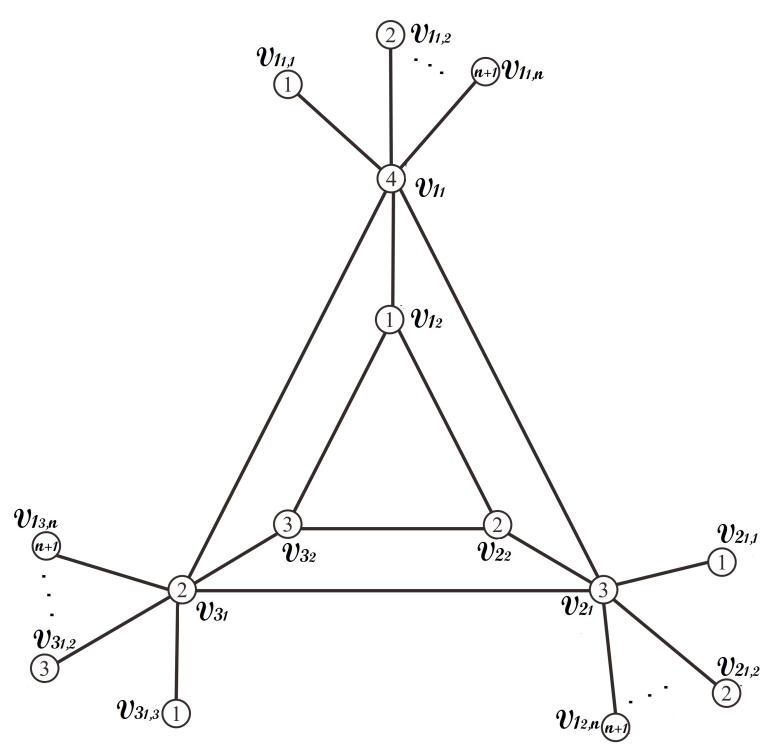

Gambar 2. Pewarnaan-4 lokasi untuk $X_{2, n}$ 
Akibatnya, diperoleh kode warna setiap titik di $X_{2, n}$ terhadap $\Pi=$ $\left\{S_{1}, S_{2}, \cdots, S_{n+1}\right\}$ sebagai berikut:

$$
\begin{aligned}
& c_{\Pi}\left(V_{1_{1}}\right)=\left(0,1,1,1, d\left(V_{1_{1}}, S_{5}\right), \cdots, d\left(V_{1_{1}}, S_{n+1}\right)\right), \\
& c_{\Pi}\left(V_{2_{1}}\right)=\left(1,0,1,1, d\left(V_{2_{1}}, S_{5}\right), \cdots, d\left(V_{2_{1}}, S_{n+1}\right)\right), \\
& c_{\Pi}\left(V_{3_{1}}\right)=\left(1,1,0,1, d\left(V_{3_{1}}, S_{5}\right), \cdots, d\left(V_{3_{1}}, S_{n+1}\right)\right), \\
& c_{\Pi}\left(V_{1_{2}}\right)=\left(0,1,1,1, d\left(V_{1_{2}}, S_{5}\right), \cdots, d\left(V_{1_{2}}, S_{n+1}\right)\right), \\
& c_{\Pi}\left(V_{2_{2}}\right)=\left(1,0,1,2, d\left(V_{2_{2}}, S_{5}\right), \cdots, d\left(V_{2_{2}}, S_{n+1}\right)\right) \text {, } \\
& c_{\Pi}\left(V_{3_{2}}\right)=\left(1,1,0,2, d\left(V_{2_{3}}, S_{5}\right), \cdots, d\left(V_{3_{2}}, S_{n+1}\right)\right), \\
& c_{\Pi}\left(V_{1_{1,1}}\right)=\left(0,2,2,1, d\left(V_{1_{1,1}}, S_{5}\right), \cdots, d\left(V_{1_{1,1}}, S_{n+1}\right)\right) \text {, } \\
& c_{\Pi}\left(V_{1_{1,2}}\right)=\left(2,0,2,1, d\left(V_{1_{1,2}}, S_{5}\right), \cdots, d\left(V_{1_{1,2}}, S_{n+1}\right)\right) \text {, } \\
& c_{\Pi}\left(V_{1_{1,3}}\right)=\left(2,2,0,1, d\left(V_{1_{1,3}}, S_{5}\right), \cdots, d\left(V_{1_{1,3}}, S_{n+1}\right)\right) \text {, } \\
& c_{\Pi}\left(V_{1_{1, n}}\right)=\left(2,2,2,1, d\left(V_{1_{1, n}}, S_{5}\right), \cdots, 0\right), \\
& c_{\Pi}\left(V_{2_{1,1}}\right)=\left(0,2,1,2, d\left(V_{2_{1,1}}, S_{5}\right), \cdots, d\left(V_{2_{1,1}}, S_{n+1}\right)\right) \text {, } \\
& c_{\Pi}\left(V_{2_{1,2}}\right)=\left(2,0,1,2, d\left(V_{2_{1,2}}, S_{5}\right), \cdots, d\left(V_{2_{1,2}}, S_{n+1}\right)\right) \text {, } \\
& c_{\Pi}\left(V_{2_{1,3}}\right)=\left(2,2,1,0, d\left(V_{2_{1,3}}, S_{5}\right), \cdots, d\left(V_{2_{1,3}}, S_{n+1}\right)\right) \text {, } \\
& c_{\Pi}\left(V_{2_{1, n}}\right)=\left(2,2,1,2, d\left(V_{2_{1, n}}, S_{5}\right), \cdots, 0\right), \\
& c_{\Pi}\left(V_{3_{1,1}}\right)=\left(0,1,2,2, d\left(V_{3_{1,1}}, S_{5}\right), \cdots, d\left(V_{3_{1,1}}, S_{n+1}\right)\right) \text {, } \\
& c_{\Pi}\left(V_{3_{1,2}}\right)=\left(2,1,0,2, d\left(V_{3_{1,2}}, S_{5}\right), \cdots, d\left(V_{3_{1,2}}, S_{n+1}\right)\right) \text {, } \\
& c_{\Pi}\left(V_{3_{1,3}}\right)=\left(2,1,2,0, d\left(V_{3_{1,3}}, S_{5}\right), \cdots, d\left(V_{3_{1,3}}, S_{n+1}\right)\right) \text {, } \\
& c_{\Pi}\left(V_{3_{1, n}}\right)=\left(2,1,2,2, d\left(V_{3_{1, n}}, S_{5}\right), \cdots, 0\right) .
\end{aligned}
$$

Karena setiap titik pada $X_{2, n}$ memiliki kode warna yang berbeda maka $c$ merupakan pewarnaan lokasi pada graf $X_{2, n}$ jadi, diperoleh bahwa $\chi_{L}\left(X_{2, n}\right) \leq n+1$. Dari pembuktian dapat dilihat bahwa $\chi_{L}\left(X_{2, n}\right) \leq n+1$ dan $\chi_{L}\left(X_{2, n}\right) \geq n+1$, untuk $n \geq 4$ sehingga, dapat disimpulkan bahwa $\chi_{L}\left(X_{2, n}\right)=n+1$ untuk $n \geq 4$.

\section{Kesimpulan}

Pada penelitian ini diperoleh bahwa:

$$
\chi_{L}\left(X_{2, n}\right)= \begin{cases}4 & \text { untuk } n=1,2,3, \\ n+1, & \text { untuk } n \geq 4 .\end{cases}
$$

\section{Ucapan Terima kasih}

Terima kasih kepada Ibu Dr. Lyra Yulianti, Ibu Dr. Haripamyu dan Bapak Bukti Ginting, M.Si selaku penguji atas kritik dan sarannya. 


\section{Daftar Pustaka}

[1] Chartrand, G., dan O.R. Oellermann. 1993. Applied and Algoritmic Graph Theory. McGraw-Hill. Inc. New York.

[2] Chartrand, G., D. Erwin, M. A. Henning, P.J. Slater dan P. Zhang. 2002. The locating chromatic number of a graph, Bull. Inst. Combin. Appl. 36: $89-101$.

[3] Welyyanti, D. 2018. Beberapa Syarat Cukup untuk Bilangan Kromatik Lokasi Hingga pada Graf Tak Terhubung. Eksakta. 19: 77 - 82 